This report was prepared as an account of work sponsored by an agency of the United States Government. Neither the United States Government nor any agency thereof, nor any of their employees, makes any warranty, express or implied, or assumes any legal liability or responsibility for the accuracy, completeness, or usefulness of any information, apparatus, product, or process disclosed, or represents that its use would not infringe privately owned rights. Reference herein to any specific commercial product, process, or service by trade name, trademark, manufacturer, or otherwise does not necessarily constitute or imply its endorsement, recommendation, or favoring by the United States Government or any agency thereof. The views and opinions of authors expressed herein do not necessarily state or reflect those of the United States Government or any agency therenf.

$\mathrm{DOE} / \mathrm{BC} / 14954--1$

DE93 010073

\title{
ADVANCED SECONDARY RECOVERY DEMONSTRATION FOR THE SOONER UNIT
}

2

Cooperative Agreement DE-FC22-93BC14954

Research \& Engineering Consultants, Inc

February 24, 1993

Award Date: October 21, 1992

Anticipated Completion Date: April, 1995

Gr

Program Manager: Mark Sippel

Principal Investigators:

Mark Sippel

James Junkin

Ronald Pritchett

Bob Hardage

Technical Project Officer: Edith Allison

Reporting Period: October, 1992 - January, 1993

"US/DOE Patent Clearance is not required prior to the publication of this document." 


\section{ADVANCED SECONDARY RECOVERY DEMONSTRATION FOR THE SOONER UNIT}

\section{Qbjectives}

The objectives of the project are to demonstrate the effectiveness of geologically targeted infill drilling and improved reservoir management to obtain maximum oil recovery from the Sooner Unit field using water injection and gas recycling as secondary methods. The first phase of the project involves an integrated multi-discipline approach to identify optimum well sites and development of a reservoir operations plan.

The second phase will involve drilling of up to three geologically targeted infill wells and establishing production/injection schedules. Reservoir simulation, transient well tests and careful production monitoring will be used to evaluate the results.

The thud phase will involve technology transfer through a series of technical papers and presentations of a short course. Emphasis will be on the economics of the project and the implemented technologies.

\section{Summary of Technical Progress}

\section{Drill ard Complete Wells}

A new 'vell was drilled and completed which confirmed and extended a reservoir compariment that was not significantly affected by pressure from water injection. The offsetting water injection well had a 6 day bottomhole shut-in pressure of 1,250 psi.

The Sooner Unit 9-21 (NESE Sec 21, T8N, R58W) was spudded on Sept. 4, 1992 and drilled to a total depth of $6,402 \mathrm{ft} K B$ (Figure 1). A drillstem stem test was run over the "D" interval from 6,282 to $6,320 \mathrm{ft}$. The recovery was $235 \mathrm{ft}$ of oil and gas cut mud. The final shut-in pressure was 533 psi and was nearly stabilized. Meaningful pressure transient analysis for permeability was not possible due to the low pressure and recovery of mostly drilling mud. The well was logged with gamma-ray, neutron-density, dual-induction, micro-log and di-pole sonic tools. Casing was run to TD and the well was completed, pumping $12 \mathrm{bbl}$ oil, $1 \mathrm{bbl}$ load water and 35 mcf gas per day after hydraulic fracture stimulation.

\section{Seismic Data Acquisiticn}

A vertical seismic profile survey was run in the Sooner Unit 10-21A well on October 12, 1992. The well was surveyed from 6,350 to $4,350 \mathrm{ft}$ at $50 \mathrm{ft}$ intervals. The purpose of the survey was to identify the seismic waveform corresponding to the "D" reservoir and establish the optimum field recording parameters. The VSP data provided the velocity control needed for seismic depth conversion and an independent reflection image of the subsurface stratigraphy for transfer to the 3-D data volume to define exactly which wavelet feature corresponds to the " $\mathrm{D}$ " reservoir. 
A 3-D seismic data volume was obtained over approximately 7.7 square-miles which produced images of the " $\mathrm{D}$ " reservoir with a frequency content exteriding from $10 \mathrm{~Hz}$ to $100 \mathrm{~Hz}$. Vibrator trucks with ground-force phase locking were utilized. Twenty receiver lines were surveyed east-west and spaced $800 \mathrm{ft}$ apart. Twenty-four source lines were oriented north-south and were spaced $600 \mathrm{ft}$ apart. The $200 \mathrm{ft}$ source spacing used on each source line allowed four vibration points to be recorded between each pair of receiver lines. A total of 732 vibrator points were recorded to create the data volume. There were minimal deviations from the normal spacing to avoid cultural obstructions such as fences, gullies, production facilities and agricultural crops. The 3-D stacking bins had a cross-sectional area of $100 \mathrm{ft}$ by $100 \mathrm{ft}$. There were approximately 21,000 stacking bins in the final processed data volume

A strong emphasis on static analysis was required because the surface topography over the Sooner Unit area has a vertical relief of $100 \mathrm{ft}$ or more across rolling hills of grassland separated by erosional features. Spectral whitening was applied to the binned data to maintain the widest possible spectrum. The " $D$ " reservoir reflections have significant energy in the range of 70 to $80 \mathrm{~Hz}$ and measurable energy exists at frequencies between 90 and $100 \mathrm{~Hz}$.

Forward modeling was performed to infer how changes in thickness and impedance of the " $\mathrm{D}$ " sandstone member can affect the character of the "D" to "J" reflection and how subtle stratigraphic changes may be revealed in the seismic reflection amplitude and frequency maps. The two most important relationships are that the " $\mathrm{D}$ " reflection peak increases as the thickness of the "D" sandstone increases and the frequency of the "D" reflection peak increases as the impedance of the " $D$ " sandstone increases. A total of 6 stratigraphic units were used in the earth model to generate the synthetic reflection responses.

Modeling indicates that an AVO analysis of the Sooner Unit 3-D seismic data would not provide definitive answers about the spatial distributions of pore fluids within the " $D$ " reservoir. Measurable AVO changes are created only when the gas saturation is greater than 90 percent, which is an unlikely condition when irreducible water saturations of 20 percent or greater are expected. There is also no significant change in the AVO response of the "D" reflection when the impedance increases within the "D" reservoir, which is analogous to increasing the water saturation. This implies that an AVO analysis would not detect water-swept areas.

The 3-D processed data volume was interpreted on a GeoQuest work station. The primary interpretation involved analysis of the " $\mathrm{D}$ " amplitude, time slices and slices with the data volume flattened on the base of the " $D$ " interval. Vertical cross sections were interpreted along and across the reservoir axis.

The " $\mathrm{D}$ " horizon relative amplitude map exhibits a number of strong lineaments that may reflect reservoir compartment boundaries. These major lineaments are also observed on the Huntsman amplitude map and, to a lesser degree, on the "J" amplitude map. These lineaments appear to persist in location and orientation through 
the "D" and Huntsman shale intervals. Faults that appear to be coincident in location and orientation with the lineaments are observed above and below the "D" horizon. Many of these faults do not offset the "D" horizon significantly. The maximum fault offset measured across the "D" is $4 \mathrm{~ms}$ to $5 \mathrm{~ms}$ which corresponds to approximately 25 to 35 feet.

Amplitude and isochron maps of the " $\mathrm{D}$ " horizon correlate well with isopach maps of the "D" based on well log data. The "D" amplitude and isocron maps indicate that the "D" horizon is contained mostly within the unit boundary and that there are several promising locations for infill drilling.

\section{Geologic and Engineering Interpretation}

The depositional setting descriptive of Graneros "D" member reservoir in the Sooner Unit is tidally influenced fluvial sandstones which were deposited, distributed, and presened in an estuarine environment. Cores from five wells, one within the Sooner Unit and four from nearby fields, were examined and described for sedimentary structures, grain size, and rock types. In particular, evidence for erosional surfaces was documented. The estruarine environment of the " $D$ " reservoir at the Sooner Unit is similar to depositional styles described by Dalrymple ${ }^{1}$, Dalrymple et al ${ }^{2}$ and Thomas et $\mathrm{al}^{3}$.

The rock type is a quartz to subarkosic arenite and grain size is silt-sized (less than $1 / 16 \mathrm{~mm}$ ) to fine-grained (to $1 / 4 \mathrm{~mm}$ ). Sorting is poor (phi deviation standard trending to 1.0 and greater), which indicates distribution or redistribution of clastic material in oscillating transport energy. Grains are rounded to subangular, although sphericity tends toward a value of 1.C (grain width in two directions is nearly the same).

A sequence stratigraphic interpretation was applied to log correlations after identification of unconformities. The core from the Sooner Unit No. 7-21 well shows a sequence of silty sandstones, interbedded shaly siltstones, and thin shale laminae. Sedimentary structures were identified in the 7-21 core that help define an estuarine environment of deposition which includes low-angle lamiriae, inclined heterolithic strata, clay and shale laminae (mud drapes), flaser beds, ripple-drift cross strata, and lenticular beds.

There are four sub-reservoirs within the "D" member which contain oil-productive sandstones. These sub-reservoir intervals have been designated $R 1, R 2, R 3$ and R4 from oldest to youngest, respectively. The spatial relationships between sub-reservoir intervals are shown in a diagrammatic west-east cross section (Figure 2). The log and core data suggest that these intervals are vertically separated by less than two feet to ten feet or more of impermeable rock types and that these intervals are not equally developed across the Sooner Unit area. In addition to the vertical separation of the four sub-reservoir intervals, sigmoidal mud-drape laminae within each interval may act as baffles and direct fluid flow. 
Sub-reservoir R1 is the oldest and deepest of the reservoir sequences. It was deposited by fluvial energy above a Lowstand Surface of Erosion (LSE). Sub-reservoir $\mathrm{R} 1$ is found along the west side of the Sooner Unit and is oriented north-northwest. The areal width is !ess than $1 / 2$ mile with a maximum thickness of $14 \mathrm{ft}$. Well-log characteristics exhibit a fining-upward profile.

Sub-reservoir R2 contains sandstones exhibiting fluvial and tidal energy influences on deposition. Sub-reservoir R2 is the most developed sandstone across the unit area and represents the second depositional cycle of the "D". The maximum thickness is 20 $\mathrm{ft}$. The sandstone consists of medium to very fine grained particles evenly graded vertically.

Sub-reservoir R3 is a sandstone interval exhibiting tidal and marine energy influences on deposition. R3 is slightly fining-upward sandstone and the interval displays a maximum productive thickness of $11 \mathrm{ft}$. This interval is developed on the north and east side of the Sooner Unit area.

Sub-reservoir R4 is the youngest and shallowest sandstone interval and exhibits a coarsening-upward sequence. Interval R4 migrated shoreward from the north to south and was deposited above a Transgressive Surface of Erosion (TSE). This reservoir interval is interpreted as being deposited contemporaneously with the major productive sandstone of the Lilli field, just north of the Sooner field. The interval is thin and lenticular with sandstone-thick axes semi-parallel to the Lilli trend. The R4 sub-reservoir interval has a net productive thickness of less than $4 \mathrm{ft}$.

Seismic maps show fault displacement of events across the " $D$ " reflectors. Disrupted amplitude events, interpreted as faults, are visible in time-section profiles from basement reflectors to the surface. A northwest-trending set of faults appears to bound thicker " $\mathrm{D}$ " sandstone and suggests that these faults were primary controls on deposition. Northeast trending faults are also present and appear to have occurred after deposition of the " $\mathrm{D}$ " reservoir.

A total of seven reservoir compartments were identified from production and pressure histories. These operational or production compartments, consisting of from one to four wells, are shown in Figure 3. These compartments are not, in every case, absolute because there is some overlapping of boundaries.

Several previously acquired pressure buildup tests were analyzed. The permeability to oil was determined to range from 10 to $100 \mathrm{md}$. Only one well, the Sooner Unit No. 228 , exhibited a buildup character which indicated reservoir barrier affects. The buildup test data indicated stimulated completions with a typical negative skin factor "S" of -3 to -4 . All wells have been hydraulically fractured.

Three conventional core studies of the " $D$ " reservoir rock were reviewed. One core was from the Sooner Unit 7-21 well and two core studies were reviewed from the Lilli field, located one mile north from the Sooner field. These core data were found to have a mean air permeability of about $10 \mathrm{md}$ and a high Dykstra-Parsons variance factor of 
0.9. Porosity and permeability data were used to develop a porosity cutoff of 8 percent for net pay calculations from logs. The derived permeability-porosity correlation was also used to estimate formation permeability from digitized porosity log data.

During recording of the seismic data, all wells were shut-in and static pressure measurements were obtained on all wells after 6 days. The static pressures ranged from 121 to 2,399 psi. These pressure data were used to identify operational reservoir compartments and to calculate the production-voidage and injection balance in the identified reservoir compartments.

The current pressure, production and injection data were used to determine that injection has been short of maintaining a balance with the current rate of reservoir voidage. Recommendations concerning operations were made to the operator which included adjustments in injection volumes and changes of production status for several wells.

The PVT analyses of the "D" reservoir fluids previously performed for the Sooner and Lilli fields were found to adequately represent the production characteristics of these fields in black-oil simulations. The Lilli field, which lies one mile north of the Sooner Unit, exhibits more homogeneous reservoir characteristics than Sooner and analyses of reservoir fluids from that field are similar to those obtained from Sooner. Successful simulation history matches of GOR and pressure were obtained from the Lilli Federal Rim No. 4-7 and 6-7 wells and the Sooner No. 2-28 well using rate-specified, singlelayer, black-oil models. This simulation study indicates that black-oil simulations and the available PVT data adequately represent reservoir fluid properties.

Several volumetric and material balance methods were used to estimate the original oil in place (OOIP) contacted by the existing wells under primary operations. Logs from wells in the unit and adjacent areas were digitized to calculate hydrocarbon pore volumes and saturations. These log data were used to calculate an original oil in place for the unit area wells. The OOIP by volumetric methods is determined to be 5.2 million stock-tank bbl.

The OOIP is determined to be 6.6 million stock-tank bbl using a method described by Calhoun 4 . The total gas produced under primary uperations for each tank battery was estimated by integrating a plot of producing gas-oil ratio versus cumulative oil produced. The static pressure data were then plotted with cumulative gas and extrapolated to atmospheric pressure to determine the total original gas in place (OGIP). Since there was originally no free gas cap, OOIP is determined by dividing the OGIP by the initial solution gas-oil ratio of $502 \mathrm{scf} / \mathrm{stb}$.

A black-oil model based on the Sooner No. 2-28 history match was used to generate a plot of primary recovery factor $(\mathrm{Np} / \mathrm{N})$ vs. average reservoir pressure. This plot exhibits linear behavior during advanced depletion under primary production and was extrapolated to a primary recovery factor of 14 percent of OOIP at an final pressure of $200 \mathrm{psi}$. Using this same plot, the recovery factor for each Sooner tank battery was determined using pressure surveys at the end of primary production in 1988. Using 
these recovery factors, the original oil in place contacted by these wells is determined to be 6.4 million stb.

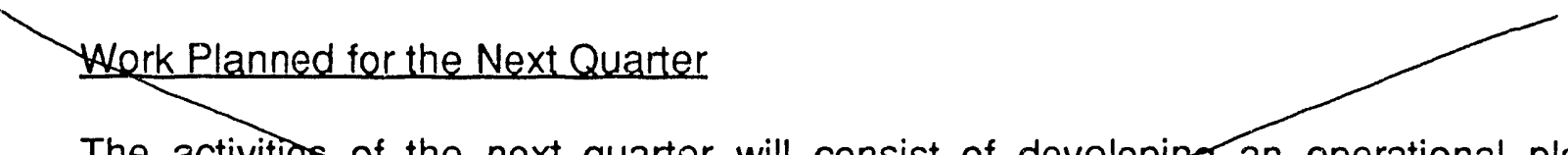

The activities of the next quarter will consist of developing an operational plan to maximize efficiency and production from each of the identified reservoir compartments. Productions tests are to be performed to help further understanding of the communication between wells.<smiles>CC1(C)CC1</smiles>

Waveform modeling and detailed seismic characterization will be focused in areas which have potential for Infill drilling potential. Prospective infill locations are characterized by operational compartments which have amplitude and isochron attributes which suggest poorly swept or drained areas. The maps of discrete sub-reservotrs will be integrated with seismic interpretations in these areas to evaluate the infilt drilling potential. Remaining moveable oil-in-place will be detemined for each operational compartment.

\section{References}

1. Dalrymple, Robert W., "Tidal Depositional Systems", Facies Models-Response to Sea Level Changes, Roger G. Walker and Noel P. James, eds., Geological Association of Canada, 1992.

2. Dalrymple, Robert W., Brian A. Zaitlin, and Ron Boyd, "Estaurine Facies Models: Conceptual Basis and Stratigraphic Implications," Journal of Sedimentary Petrology, vol. 62, no. 6, November 1992, p. $1130-1146$.

3. Thomas R.G., Derald G. Smith, James M. Wood, John Visser, E. Anne Calverley-Range, and Emlyn H. Koster, "Inclined Heterolithic Stratification terminology, description, interpretation and significance," Sedimentary Geology, v. 53, p. $123-179,1987$.

4. Calhoun, John C. Jr., Fundamentals of Reservoir Engineering, University of Oklahoma Press, pg. 229-231, 1947. 


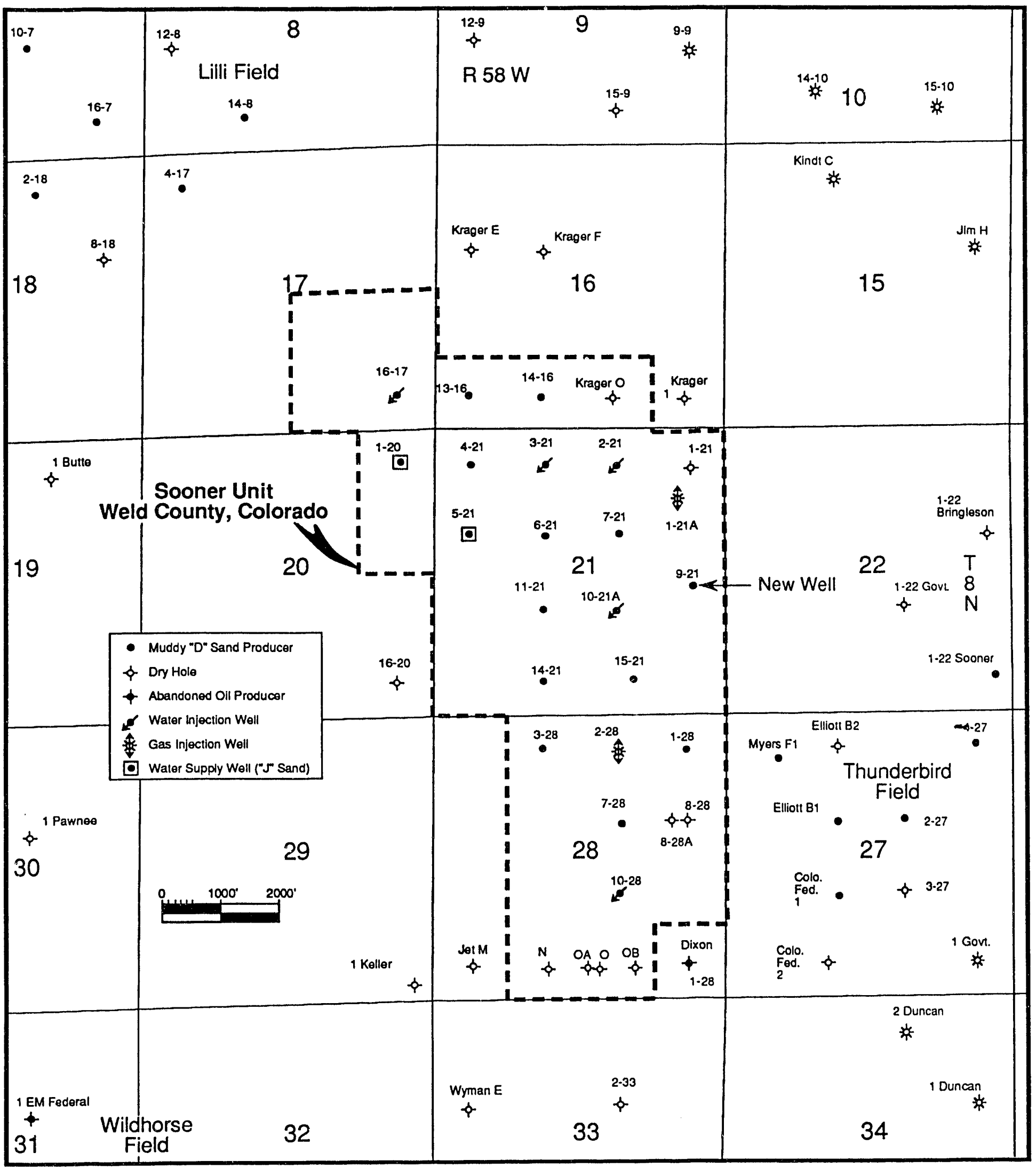

Research \& Engineering Consultants, Inc.

Figure 1

Sooner Unit Field Area 


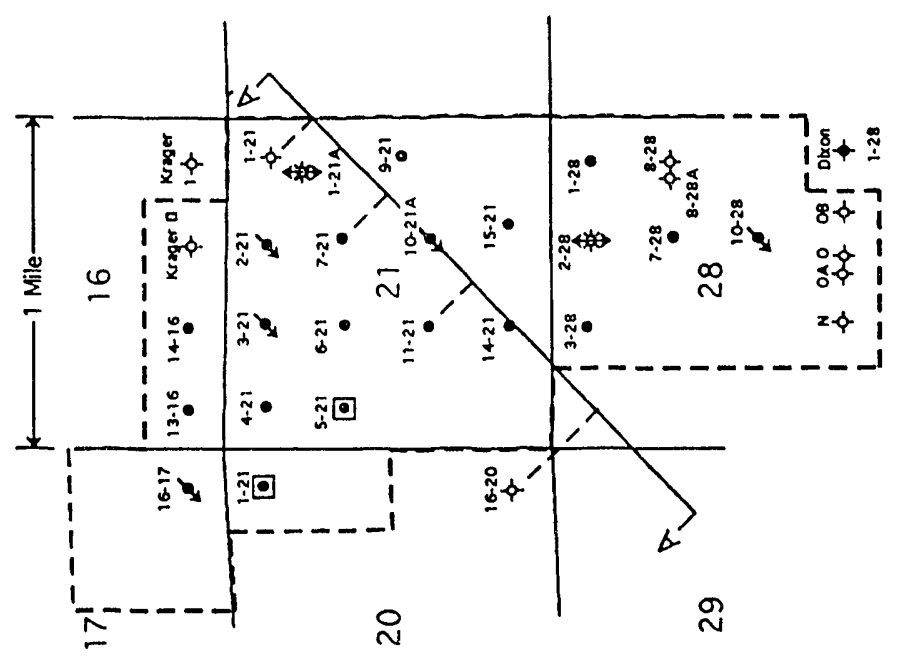

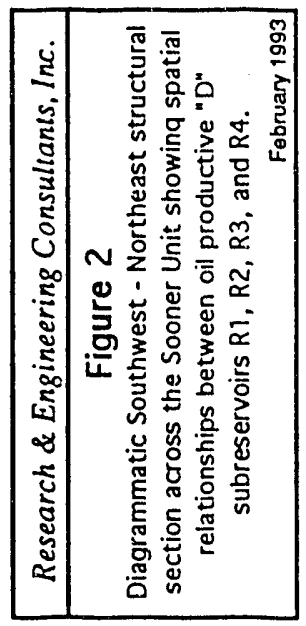

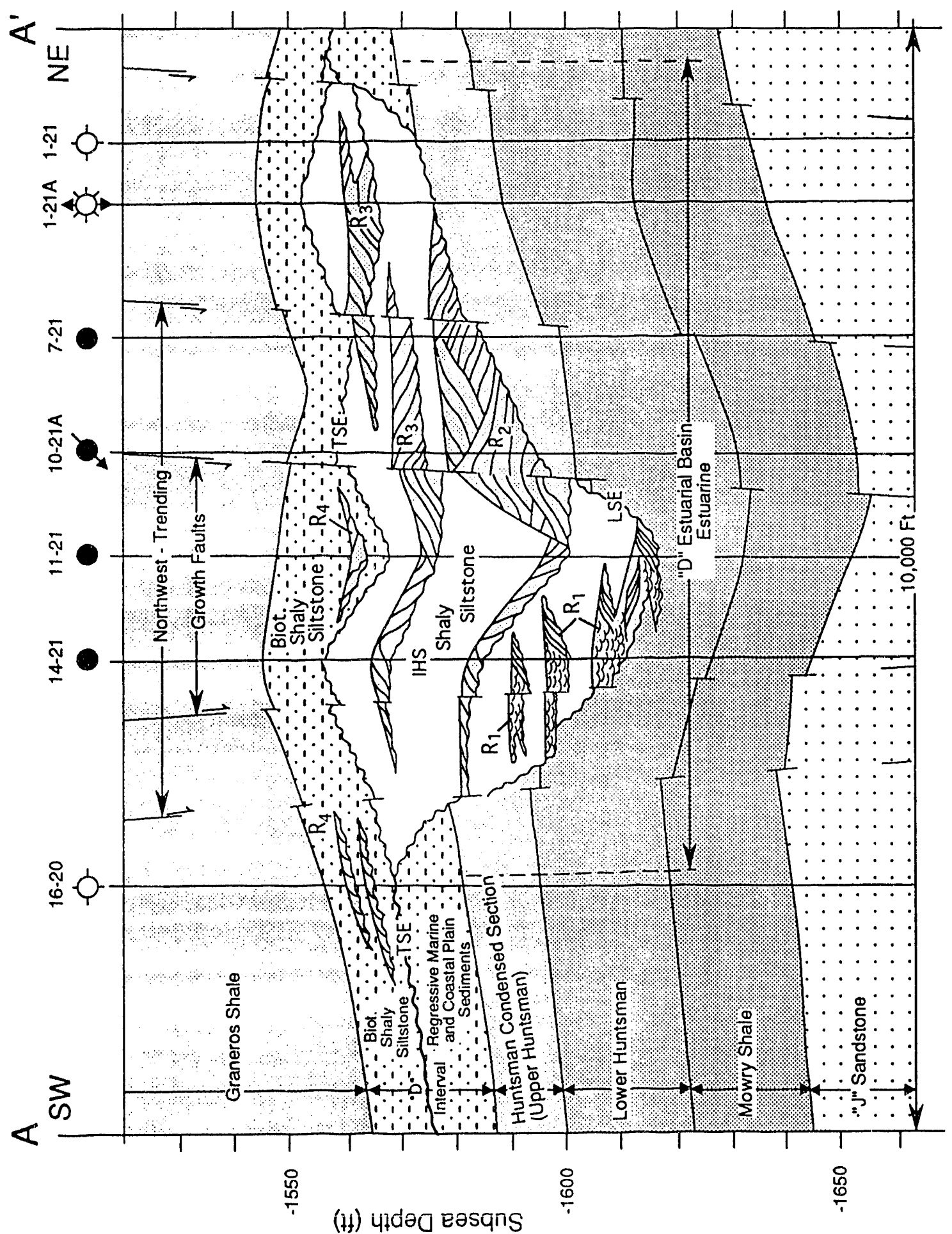

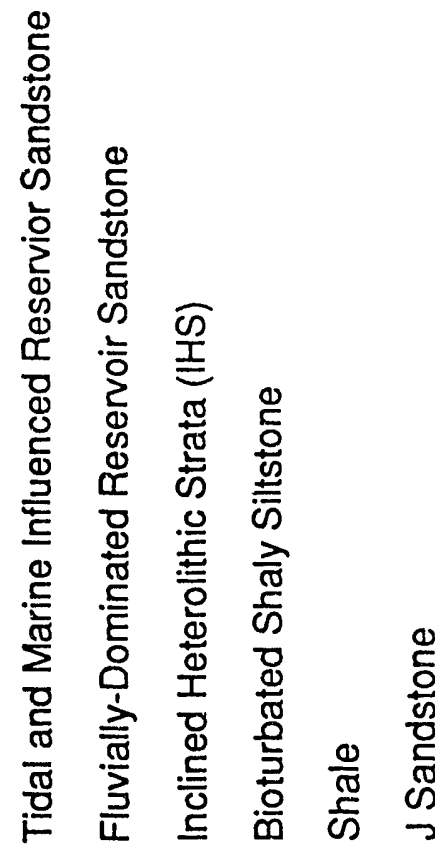
W $\square[\because \div \square$ 


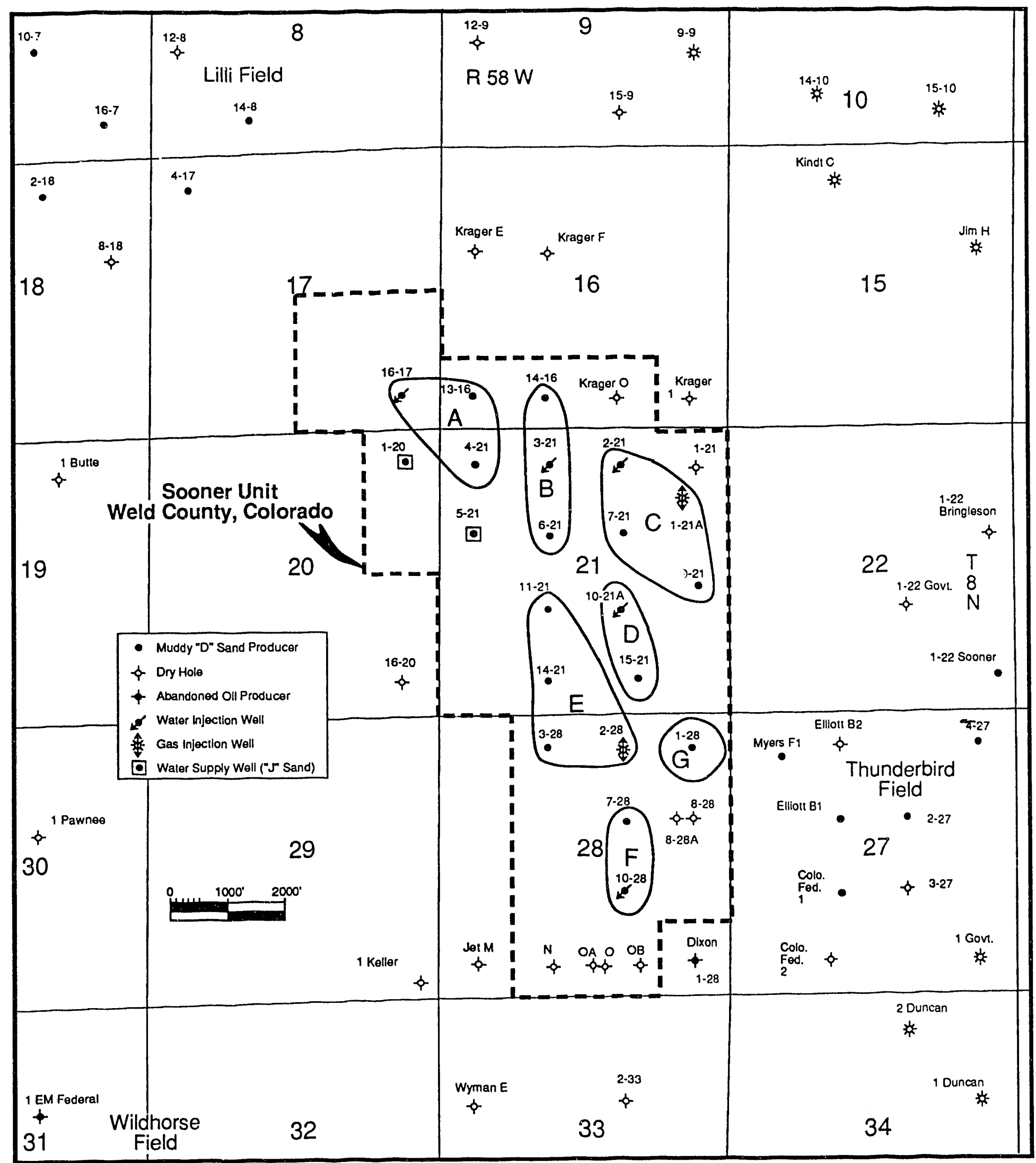

Research \& Engineering Consultants, Inc.

Figure 3

Operational Compartments Seven Well-Groups A through G 

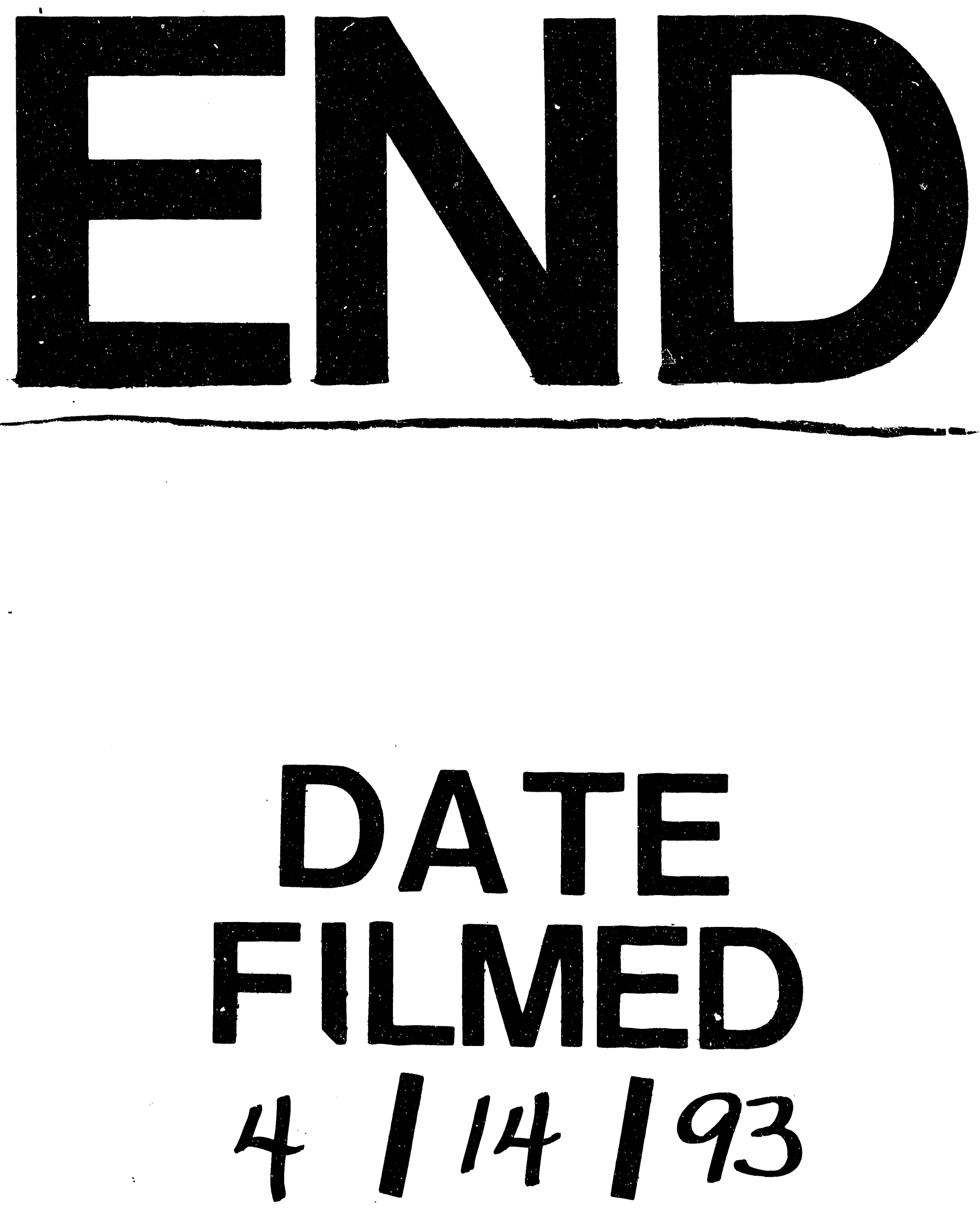
